\title{
BMJ Open Cardiovascular disease risk factors among school children of Bangladesh: a cross-sectional study
}

\author{
T M Manjurul Islam, ${ }^{1}$ Palash Chandra Banik (D) , ${ }^{2}$ Lingkan Barua (D) ,2 \\ Sheikh Mohammed Shariful Islam (D) ,", Shahanaz Chowdhury, ${ }^{1}$ \\ M S A Mansur Ahmed ${ }^{1}$
}

To cite: Islam TMM, Banik PC, Barua L, et al. Cardiovascular disease risk factors among school children of Bangladesh: a cross-sectional study. BMJ Open 2020;10:e038077. doi:10.1136/ bmjopen-2020-038077

- Prepublication history and additional material for this paper is available online. To view these files, please visit the journal online (http://dx.doi.org/10. 1136/bmjopen-2020-038077).

Received 26 February 2020 Revised 16 June 2020 Accepted 25 September 2020

Check for updates

(C) Author(s) (or their employer(s)) 2020. Re-use permitted under CC BY-NC. No commercial re-use. See rights and permissions. Published by BMJ.

${ }^{1}$ Community Medicine, Bangladesh Institute of Health Sciences, Dhaka, Dhaka District, Bangladesh

${ }^{2}$ Noncommunicable Diseases, Bangladesh University of Health Sciences, Dhaka, Bangladesh

${ }^{3}$ Exercise and Nutrition

Sciences, Deakin University Faculty of Health, Burwood,

Victoria, Australia

${ }^{4}$ Cardiovascular Division, The George Institute for Global Health, Sydney, New South Wales, Australia

Correspondence to

Dr Lingkan Barua;

lingkanbarua@gmail.com

\section{ABSTRACT}

Objective Primarily, we assessed the distribution of cardiovascular disease (CVD) risk factors among school children living in urban and rural areas of Bangladesh. In addition to this, we sought the association between place of residence and modifiable CVD risk factors among them. Design, setting and participants This cross-sectional study was conducted among 854 school children (aged 12-18 years) of Bangladesh. Ten public high schools (five from Dhaka and five from Sirajgonj district) were selected randomly and subjects from those were recruited conveniently. To link the family milieu of CVD risk factors, a parent of each children was also interviewed.

Primary and secondary outcome measures Distribution of CVD risk factors was measured using descriptive statistics as appropriate. Again, a saturated model of binary logistic regression was used to seek the association between place of residence and modifiable CVD risk factors.

Results Mean age of the school children was 14.6 \pm 1.1 years and more than half $(57.6 \%)$ were boys. Overall, $4.4 \%$ were currently smoker (urban-3.5\%, rural-5.2\%) with a strong family history of smoking (42.2\%). Similar proportion of school children were identified as overweight (total 9.8\%, urban 14.7\%, rural 5\%) and obese (total $9.8 \%$, urban $16.8 \%$, rural $2.8 \%$ ) with notable urban-rural difference. More than three-fourth $(80 \%)$ of them were physically inactive with no urban-rural variation. Only $2.4 \%$ consumed recommended fruits and/ or vegetables (urban-3.1\%, rural-1.7\%). In the adjusted model, place of residence had higher odds for having several modifiable CVD risk factors: current smoking (OR: $1.807, \mathrm{Cl} 0.872$ to 3.744), inadequate fruits and vegetables intake (OR: 1.094, Cl 0.631 to 1.895), physical inactivity (OR: 1.082 , Cl 0.751 to 1.558 ), overweight (OR: $3.812, \mathrm{Cl} 2.245$ to 6.470 ) and obesity (OR: 7.449 , Cl 3.947 to 14.057 ).

Conclusions Both urban and rural school children of Bangladesh had poor CVD risk factors profile that demands further nation-wide large scale study to clarify the current findings more precisely.

\section{INTRODUCTION}

Cardiovascular disease (CVD) is a major health emergency and number one cause of premature death across the globe. Lowincome and middle-income countries are
Strengths and limitations of this study

- Inclusion of both urban and rural school children to explore a wide range of established cardiovascular risk factors is its main strength.

- Incorporation of parental data like sociodemographic attainment, behavioural risk factors and presence of chronic diseases will help to link the family milieu.

- Being cross-sectional in nature, the study could not establish causality due to the lack of temporal evidence.

- Application of recall method to collect data on cardiovascular disease risk factors was associated with the probability of recalled bias.

- Convenient sampling method to recruit study subjects elevate the risk of selection bias.

disproportionally affected, counted $80 \%$ of deaths due to CVD. ${ }^{1}$ In this context, South Asians are more vulnerable racial group having high prevalence of coronary heart disease as compared with other ethnicity. ${ }^{2}$ Among the South Asian countries, China and India are carrying huge burden of CVD due to rapid demographic, social and economic transition. As a neighbouring country of India, in Bangladesh, CVD accounts for 27\% of deaths due to all causes, whereas noncommunicable diseases (NCD) account for $52 \%$ of all deaths. ${ }^{3}$ Last, NCD risk factors survey of Bangladesh ${ }^{4}$ reflected clean-cut urban-rural variation in distribution of risk factors and though rural population was socioeconomically deprived but high risk factor burden was reported for them. Moreover, clustering phenomenon was also observed among the Bangladeshi population that demands special strategy for prevention and control of NCD. ${ }^{4}$ Hence, recent initiatives have specifically targeted children and adolescent for NCD prevention programme.

Atherosclerosis is a major underlying mechanism of CVD that initiated in childhood and 
under the influence of certain conventional risk factors it progresses gradually. ${ }^{5}$ Though it begins during childhood, throughout the life course, the process is modified by the interaction of genetic and environmental factors. ${ }^{2}$ In this regard, familial history of CVD is important that reflects genetic susceptibility and interactions between genetic, environmental, cultural and behavioural factors. ${ }^{6}$ Previous research suggests that one of factors contributing to the development of atherosclerosis is the environment. Based on a population based prospective study, Lind $e t$ al concluded that circulating levels of organic pollutants were associated with atherosclerosis. ${ }^{7}$ They also suggested that organic pollutants may be an independent risk factor for myocardial infarction. ${ }^{7}$ However, this multiple risk factors mediated underlying atherosclerotic progress remain apparent and hence the significance underscores the necessity of screening programme among children and youth, which may help to predict future burden. ${ }^{8}$ Children are particularly vulnerable to the negative health aspects associated with urban life, as they have the least independence from and are most manipulated by their living and built environment. ${ }^{9}$ Such urban trends are fuelling levels of overweight and obesity that significantly impact on the cardiovascular health of city living children. ${ }^{10}$ Worldwide, 1 in 10 school-aged children is estimated to be overweight. ${ }^{11}$ Globally in 2010, the number of overweight children under the age of 5 is estimated to be over 42 million. Close to 35 million of these are living in developing countries. ${ }^{12}$ There is strong evidence that an epidemic of childhood obesity has led to a significant increase in the prevalence of cardiovascular risk factors, which, if left unchecked, is likely to lead to an epidemic of premature CVD. In these circumstances, current study aims to assess the prevalence of CVDs risk factors among urban and rural school going children of Bangladesh. In addition to this, we sought the association of different modifiable CVD risk factors with the living area.

\section{METHODS}

\section{Study design}

A cross-sectional study was conducted from January 2018 to December 2018 among the school children of selected rural and urban area of Bangladesh. First, we used multistage clustered random sampling to select 10 public high schools, 4 from Dhaka city and 5 from Sirajganj district, representing urban and rural population, respectively (see online supplemental material 1). Finally, a total of 854 (urban-427, rural-427) school children of 12-18 years of age were selected using convenient sampling technique (see online supplemental material 2). To link the family milieu of CVD risk factors, a parent of each children was also interviewed to elucidate their sociodemographic characteristics, behaviours and presence of comorbidity.

\section{Data collection and measurement}

Data were collected at mentioned schools through face to face interview using a pretested questionnaire (see online supplemental material 3). Both the children and their parents were interviewed and informed written consent was taken from the parents on behalf of the children at data collection site. Based on the objectives and variables of the study, data were collected from the children about their sociodemographic background, behavioural risk factors and physical measurement. The parents were interviewed for educational attainment, occupation, presence of chronic diseases and their behaviours like tobacco use and alcohol intake.

Physical measurement (height, weight) of the children was carried out following standard method and adequate privacy. The standing height was measured with a height measuring scale with minimal cloths. Then, the body weight was measured using digital weight measuring machine and recorded to the nearest $0.1 \mathrm{~kg}$. Based on height and weight, the obesity was determined using body mass index (BMI) and it was derived as weight $(\mathrm{kg})$ / height in $\mathrm{m}^{2}$.

\section{Ascertainment of key variables \\ Current tobacco user}

Those who consumed tobacco in any form in the past 30 days were considered as 'current' user. ${ }^{4}$

\section{Current alcohol user}

Those who consumed alcohol in the past 30 days were considered as 'current' alcohol user. ${ }^{4}$

\section{Inadequate fruits and/ or vegetables intake}

Less than five servings of fruits and/or vegetable a day was considered as inadequate. ${ }^{4}$

\section{Added salt intake}

It is defined for those participants who used to take dietary salt during eating meal.

\section{Physical inactivity}

Physical inactivity was defined as moderate to vigorous activity $\leq 60 \mathrm{~min} /$ day for all 7 days of previous week.

\section{Adiposity}

BMI was used to assess the status of adiposity and classified according to WHO growth reference. ${ }^{13}$ We categorised adiposity as underweight, normal weight, overweight and obesity.

\section{Quality assurance}

Working Groups for data collection was formed with the help of experts and volunteers. The group was divided into two subgroups, namely Intellectuals Group (IG) and Volunteers Group (VG). The IG was formed with the help of experts of Community Medicine, Biostatistics, Health Education \& Health Promotion and NCDs. This IG helped in making a training module. They trained the volunteers and discussed all the steps of the study. On the other hand, the VG were formed with the help of a group of undergraduate medical, dental and physiotherapy students. Initially, we got the name of 20 students 
as volunteers. Among 20 students, 12 students were selected based on two post-training evaluation test for the data collection. The VG members helped in pretesting of questionnaire \& data collection in Dhaka and Sirajganj, northern part of Bangladesh.

We applied specific measures to improve the quality of the study: (a) the questionnaire was translated into local language and pretested to detect any inconsistency, unclear wording or unusual longer duration to administer; (b) to minimise the recalled bias, the participants got enough time to answer each question and support from their parent was also considered where appropriate; (c) using show cards to better explain dietary servings; (d) maintaining adequate privacy during physical measurements and (e) using robust equipment for physical measurements.

\section{Patient and public involvement}

We collected data from the children who were the students of selected public schools of Dhaka and Sirajganj districts. We also interviewed the parent of the school children. However, none of them were involved directly in the setting of the research question or outcome measures. They did not have any role in designing or implementing this work or interpretation of the results.

\section{Ethical consideration}

All parents gave their informed written consent on behalf of their children to participate in the study (see online supplemental material 4).

\section{Data processing and analysis}

All 854 responses were reviewed thoroughly for consistency and completeness. Total 8 responses were found incomplete or inconsistent and hence the final analysis comprised of 846 responses (urban 423 and rural 423). All the data were entered into the computer software Statistical Package for Social Science (SPSS) V.20.0 for Windows (SPSS, Chicago. Illinois, USA).

All estimates of precision were presented at $95 \%$ CI in the tables. Descriptive analysis included mean, SD, median and IQR, frequencies and percentages where appropriate. In this study, the $\mathrm{p}$ value (two-sided) was considered statistically significant at the threshold of $\mathrm{p}<0.05$. To find the association between CVD risk factors and place of residence, we run a saturated/full model of binary logistic regression. In the saturated/full model, we considered all modifiable CVD risk factors (except smokeless tobacco and alcohol intake as both had low percentage, $0.5 \%$ and $0.8 \%$, respectively) according to the rules of variable selection in regression. ${ }^{1415}$ For binary logistic regression analysis, we calculated ORs and 95\% CI for each independent variable. We used the STROBE (Strengthening the Reporting of Observational Studies in Epidemiology) guidelines for reporting the results of cross-sectional observational study (see online supplemental material 6).
RESULTS

\section{Sociodemographic features of the school children}

Sociodemographic features of the school children are presented in table 1. More than three-fourth of them remained below 16 years of age group and their mean age was $14.6 \pm 1.1$ years, for both urban and rural area. In urban area, the boys to girls ratio of participation was almost equal but a vast difference was reflected in rural area where number of boys was twice of the girls. This is why boys were predominant $(57.6 \%)$ in this study. Most of the school children $(95.4 \%)$ were from low-income background and their urban residents were economically more solvent (median monthly income US\$366) than the rural residents (median monthly income US\$122). The overall median monthly income was US $\$ 183$ with an IQR of US\$122 to US $\$ 366$.

\section{CVD risk factors burden among the parents}

Major NCDs were highly prevalent among the parent of respondents and the burden was higher in urban area compared with rural. Among them, the prevalence of diabetes $(21.6 \%)$ was highest and hypertension $(15.1 \%)$ was next to it, considering both areas together. More than half $(66.4 \%)$ of them were tobacco users and urban residents were mostly habituated to this behavioural risk factor. Illiteracy was not differed so far among the parents (mother 11.6\%, father 9.3\%) but urban-rural comparison of illiteracy reflected very high difference (urban $=5.5 \%$, rural $=36.4 \%$ ), seven times higher in rural area compared with urban (table 2).

\section{Distribution of CVD risk factors among the school children}

The prevalence of different CVD risk factors according to urban-rural distribution is presented in table 3. Among the total school children, $4.4 \%$ were currently tobacco users and the habit was mostly practiced in rural area. Abnormal body weight in terms of underweight, overweight and obesity was one-fourth (26.7\%) of total school children. The known CVD risk factors overweight and obesity comprised $19.6 \%$ of total school children and more than half of abnormal body weight. Here, the burden of underweight was higher among the school children who lived in rural area, but overweight and obesity was higher among the residents of urban area. Their dietary habit was unhealthy as they took inadequate fruits and/ or vegetables (97.2\%) and added salt in meal $(67 \%)$. Practice of added salt intake (daily/occasionally) was more in rural area compared with urban but not differed so far (rural $36.2 \%$ vs urban $30.75 \%$ ). More than three-fourth of the school children were physically inactive $(81.7 \%)$ and habit of alcohol intake was high among the urban children compared with rural (urban 1.2\%, rural $0.5 \%$ ). The physical inactivity as well as fruits and vegetables intake did not show any mentionable urbanrural difference among them.

The associations between location and modifiable CVD risk factors are presented in table 4 . Here, place of residence had higher odds for having several modifiable 
Table 1 Sociodemographic characteristics of the respondents $(n=846)$

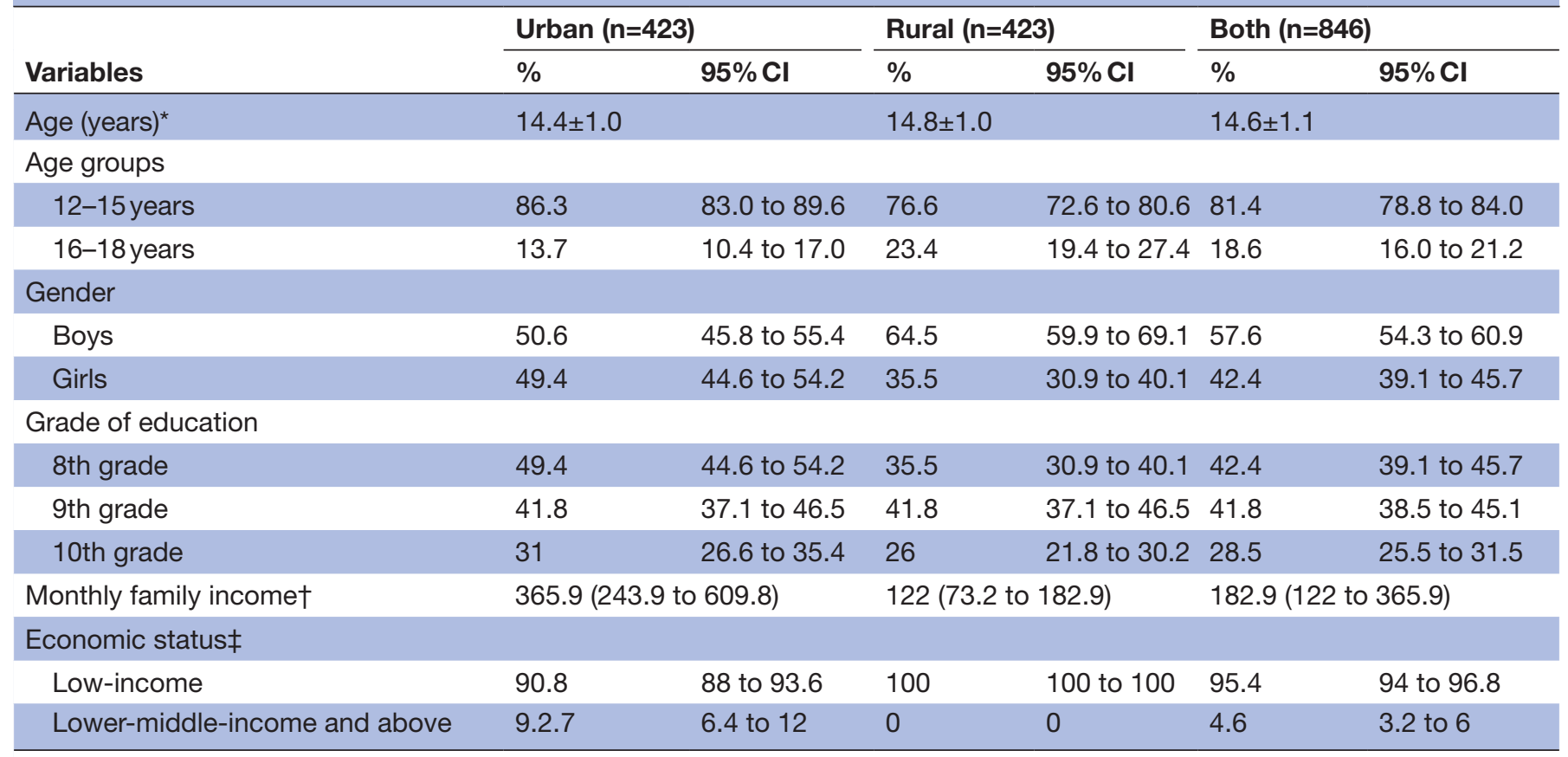

*Presented as mean \pm SD.

†Presented as median (IQR), the unit was US\$ as per 9 July 2018 currency. $\ddagger$ According to the July 2018 per-capita GNI and the World Bank calculation. $\mathrm{GNI}$, gross national income.

CVD risk factors both in unadjusted and adjusted model: current smoking (unadjusted, OR 1.492; adjusted, OR 1.807), inadequate fruits and/ or vegetables intake (unadjusted, OR 1.072; adjusted, OR 1.094), overweight (unadjusted, OR 7.026; adjusted, OR 3.812) and obesity (unadjusted, OR 3.288; adjusted, OR 7.449). However, place of residence showed higher odds for physical inactivity (adjusted OR 1.082) in adjusted model compared with unadjusted. In both adjusted and unadjusted model, place of residence had significant increase in odds for having overweight $(\mathrm{p}<0.001)$ and obesity $(\mathrm{p}<0.001)$.

\section{DISCUSSION}

Results of current study demonstrated that CVD risk factors burden among Bangladeshi school going children was high and also at alarming level with negligible urbanrural difference. Among the well-known risk factors, prevalence of smoking $(4.4 \%)$ was 1.5 times higher than the nationally representative data of 'Global Youth Tobacco survey 2013' conducted in Bangladeshi children $(2.9 \%){ }^{16}$ This percentage is much greater for the children of Pakistan ${ }^{17}$ and India, ${ }^{18}$ representing $6 \%$ and $8.2 \%$ smoker, respectively. It has evidenced that family milieu plays an important role in tobacco addiction among children and the prevalence is also high among those having such family history of tobacco use. ${ }^{19}$ In this regard, children of current study showed strong family milieu as more than half of their parents were habituated to tobacco use, among which two-third were smoker and rest were smokeless tobacco user. We found that the children of rural area were more habituated to tobacco (smoking/smokeless) use compared with the urban area. The possibility includes parental illiteracy and behaviour of tobacco consumption. In this study, both illiteracy and tobacco consumption was higher among rural parents compared with the urban. This adult pattern of tobacco use among family member is significant as the proportion of smoker exceeded the nationally representative data of the NCD risk factors survey Bangladesh 2010. ${ }^{4}$ According to NCD risk factors survey, the rate of adult tobacco user was $23.6 \%$; among them, $18.9 \%$ (less than half of the present study) were current smokers and 21.2\% (almost similar to the present study) were smokeless tobacco users. Again, the prevalence of diabetes and hypertension among the parents was also greater than the above mentioned survey. ${ }^{4}$ The possible causes behind this result variation is that the findings of the present study were among respondent's family, not among individual member. Besides this, the survey was conducted 8 years ago and was population based where most of the subjects ignored their health problem, even 3 in 10 subjects never measured their blood pressure and $83 \%$ of the survey population never measured their blood glucose level.

Findings of current study about body weight were mixed. This is because the burden of abnormal body weight in terms of underweight $(7.1 \%)$, overweight $(9.8 \%)$ and obesity $(9.8 \%)$ was not differed so far. Simultaneous presence of these three varieties of body weight 
Table 2 Sociodemographic, medical and behavioural characteristics of the parents, $n=846$

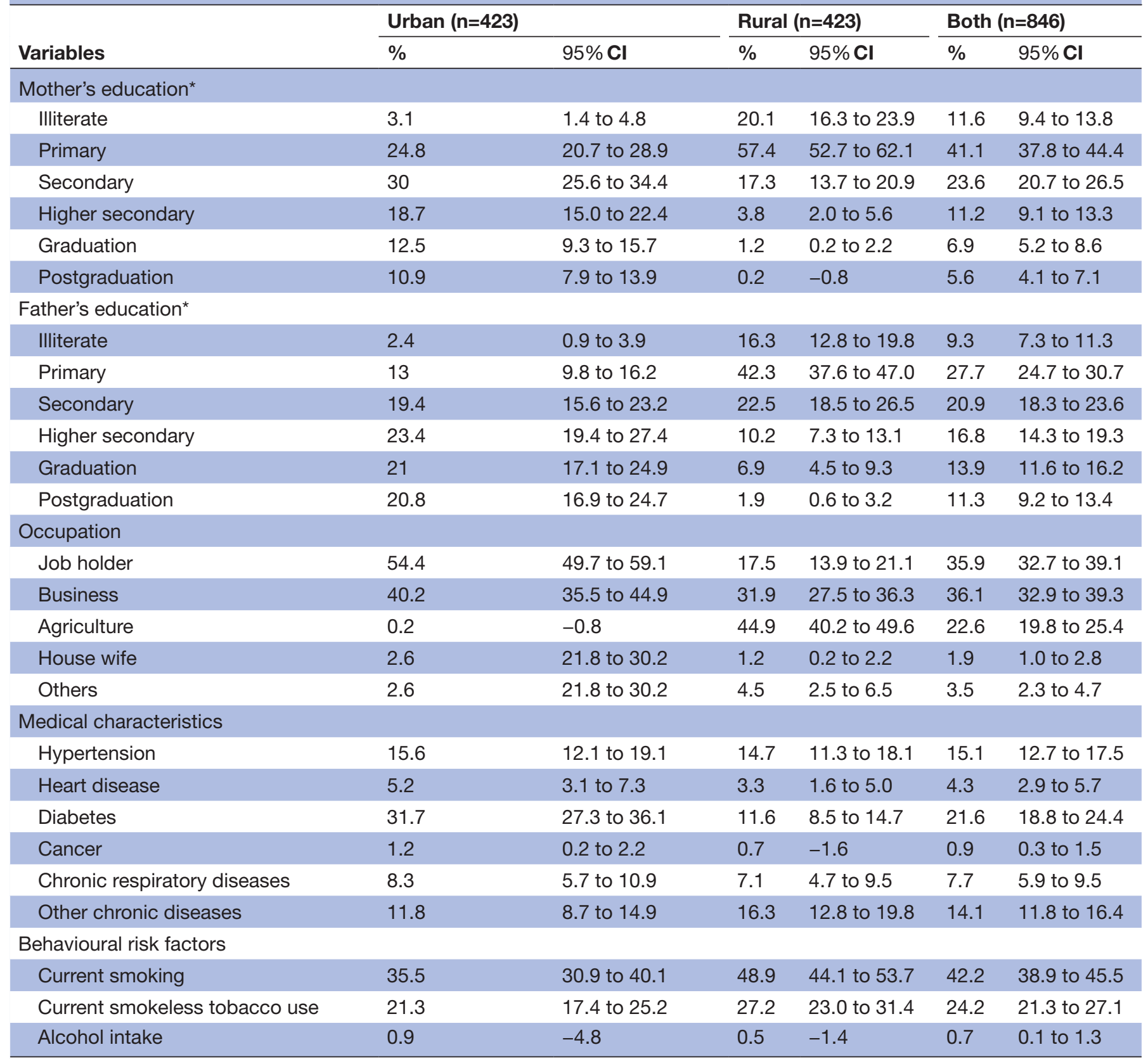

*According to education structure of Bangladesh, Ministry of Education, Government of the People's Republic of Bangladesh.

indicates impending nutritional transition occurring in Bangladeshi children. Same type of findings regarding body weight was also stated by a Bangladeshi study of Bulbul et al and a study of Istanbul (Turkey) where coexistence of underweight and overweight was found. ${ }^{2021}$ The prevalence of overweight and obesity of current study is comparable with the mentioned study of Bulbul et al where $12.24 \%$ (higher than the present study) of the secondary school children of Bangladesh were overweight and $2.96 \%$ (lower than the present study) were obese. $^{20}$ This result variation may be due to difference of age group. In the above mentioned study, the students were 13-15 years age group where current study enrolled different age categories.

Unhealthy eating patterns in childhood can adversely affect health and contribute to chronic disease in later life. Current study detected a vast portion of school children used to take less than the recommended ( $\geq 5$ servings per day) fruits and/or vegetables. Compared with other neighbouring country of South East Asia (SEA), this finding is very alarming. This is because in a study conducted among school adolescents of five SEA countries (India, Indonesia, Myanmar, Sri Lanka, Thailand) with national data showed much less $(76.3 \%)$ prevalence of inadequate 
Table 3 CVD risk factors among the school children of Bangladesh, $n=846$

\begin{tabular}{|c|c|c|c|c|c|c|}
\hline \multirow[b]{2}{*}{ CVD risk factors } & \multicolumn{2}{|c|}{ Urban $(n=423)$} & \multicolumn{2}{|c|}{ Rural $(n=423)$} & \multicolumn{2}{|c|}{ Both $(n=846)$} \\
\hline & $\%$ & $95 \% \mathbf{C l}$ & $\%$ & $95 \% \mathbf{C l}$ & $\%$ & $95 \% \mathrm{Cl}$ \\
\hline Current smoker & 3.5 & 1.7 to 5.3 & 5.2 & 3.1 to 7.3 & 4.4 & 3.0 to 5.8 \\
\hline Current smokeless tobacco user & 0 & 0 & 0.9 & -3.0 to 1.8 & 0.5 & 0.02 to 1.0 \\
\hline Current alcohol user & 1.2 & 0.2 to 2.2 & 0.5 & -0.2 to 1.2 & 0.8 & 0.2 to 1.4 \\
\hline Inadequate fruits and/ or vegetables intake & 96.9 & 95.2 to 98.6 & 98.3 & 97.1 to 99.5 & 97.6 & 96.6 to 98.6 \\
\hline \multicolumn{7}{|l|}{ Added salt intake } \\
\hline Daily & 30.5 & 26.1 to 34.9 & 38.8 & 34.2 to 43.4 & 34.6 & 31.4 to 37.8 \\
\hline Occasional & 31.0 & 26.6 to 35.4 & 33.6 & 29.1 to 38.1 & 32.3 & 29.1 to 35.5 \\
\hline Physical inactivity & 82.5 & 78.9 to 86.1 & 80.9 & 77.2 to 84.6 & 81.7 & 79.1 to 84.3 \\
\hline $\mathrm{BMI}, \mathrm{kg} / \mathrm{m}^{2}($ mean $\pm \mathrm{SD})$ & \multicolumn{2}{|l|}{$21.1 \pm 3.8$} & \multicolumn{2}{|c|}{$18.9 \pm 2.7$} & \multicolumn{2}{|c|}{$20 \pm 3.5$} \\
\hline \multicolumn{7}{|l|}{ Abnormal body weight } \\
\hline Underweight & 4.5 & 2.5 to 6.5 & 9.7 & 6.9 to 12.5 & 7.1 & 5.4 to 8.8 \\
\hline Overweight & 14.7 & 11.3 to 18.1 & 5.0 & 2.9 to 7.1 & 9.8 & 7.8 to 11.8 \\
\hline Obesity & 16.8 & 13.2 to 20.4 & 2.8 & 1.2 to 4.4 & 9.8 & 7.8 to 11.8 \\
\hline
\end{tabular}

.BMI, body mass index; CVD, cardiovascular disease.

fruits and vegetable consumption compared with current study $(97.2 \%) .{ }^{22}$ Again, results of the mentioned multinational study ${ }^{22}$ also coincides with the prevalence of other two studies-one among seven African countries $(77.5 \%)^{23}$ and other in the American high school students $(78.6 \%) .{ }^{24}$ This pattern of cross-national variation could be due to fruits and vegetable availability, income and urbanisation rate. ${ }^{22} 25$

In the current study, most of the participants were physically inactive based on the recommended duration of activity $>60 \mathrm{~min} /$ day for all 7 days of previous week. This physical inactivity level is more than the other studies conducted among school children of India ${ }^{26}$ and Malaysia $^{27}$ representing $62.5 \%, 56.2 \%$ and $24.5 \%$ respectively. The possible cause of variation is different methods of physical activity measurement. In the mentioned comparable studies, India followed same method as current study. But Malaysian study applied Physical Activity Questionnaire for Older Children (PAQ-C) that categorised as low, moderate and high. Again, Indian study was conducted among urban children but current study included both urban and rural participants.

Overall, urban-rural distribution of current study showed CVD risk factors, namely overweight and obesity, alcohol intake, physical inactivity and major NCDs among parents were highly prevalent in the children of urban area. On the other hand, CVD risk factors including tobacco use, inadequate fruits and/or vegetable intake, rate of illiteracy and low socioeconomic status were prevalent among rural participants. High prevalence of overweight and obesity in urban area is also stated by the previously mentioned countrywide epidemiological study of Bangladesh. ${ }^{20}$ Findings regarding

Table 4 Association of modifiable CVD risk factors with place of residence, $n=846$

\begin{tabular}{|c|c|c|c|c|c|c|}
\hline \multirow[b]{2}{*}{ Risk factors } & \multicolumn{3}{|c|}{ Place of residence (urban, rural) } & \multicolumn{3}{|c|}{ Place of residence (urban, rural) } \\
\hline & $P$ value & Unadjusted OR & $95 \% \mathrm{Cl}$ & $P$ value & Adjusted OR & $95 \% \mathbf{C l}$ \\
\hline Current smoking & 0.242 & 1.492 & 0.763 to 2.918 & 0.112 & 1.807 & 0.872 to 3.744 \\
\hline $\begin{array}{l}\text { Inadequate fruits and/or } \\
\text { vegetables intake }\end{array}$ & 0.792 & 1.072 & 0.639 to 1.799 & 0.749 & 1.094 & 0.631 to 1.895 \\
\hline Added salt intake & $0.001^{*}$ & 0.610 & 0.457 to 0.815 & $0.013^{*}$ & 0.678 & 0.500 to 0.921 \\
\hline Physical inactivity & 0.534 & 0.895 & 0.632 to 1.269 & 0.673 & 1.082 & 0.751 to 1.558 \\
\hline Underweight & $0.004^{*}$ & 0.438 & 0.250 to 0.768 & 0.068 & 0.589 & 0.333 to 1.041 \\
\hline Overweight & $<0.001^{*}$ & 7.026 & 3.751 to 13.159 & $<0.001^{*}$ & 3.812 & 2.245 to 6.470 \\
\hline Obesity & $<0.001^{*}$ & 3.288 & 1.965 to 5.502 & $<0.001^{*}$ & 7.449 & 3.947 to 14.057 \\
\hline
\end{tabular}

We adjusted all variables included in the table: current smoking, inadequate fruits and/ or vegetables intake, added salt intake, physical inactivity, underweight, overweight and obesity.

*Significant $p$ value.

CVD, cardiovascular disease. 
alcohol intake were consistent with the NCD risk factors survey of Bangladesh where urban population showed high prevalence. ${ }^{4}$ The possible explanation of urban-rural variation of alcohol consumption includes influence of social and cultural factors like religious cultural practices, community and family relationships, economic conditions, the availability of alcohol and the enforcement of alcohol laws. ${ }^{28}$ In current study, urban-rural variation of CVD risk factors possibly due to the result of urbanisation and it is believed that in addition to genetic or familial predisposition, environmental factors like undernourishment in early life, adoption of an urbanised lifestyle or a combination of both factors may contribute to high prevalence of NCD risk factors. In this study, parents of rural participants had low socioeconomic status as well as education level and both are considered as the influencing factors for adoption of harmful habits like unhealthy diet and tobacco use among the family members. ${ }^{29}$

In this study, place of residence had higher odds for having several modifiable CVD risk factors including current smoking, inadequate fruits and/or vegetables intake, physical inactivity, overweight and obesity. Previous studies reported significant urban-rural difference for tobacco consumption and the rate was higher among rural compared with urban children, similar to our study. ${ }^{30}$ The BMI of school children is significantly differed between urban and rural area was also justified by an Indian study of Punjab. ${ }^{31}$ Again, two other studies reported same difference in dietary pattern among urban and rural children. ${ }^{32}{ }^{33}$ It was noted that children of low-income communities and rural area has less access to healthy foods environment that exposes them to unhealthy diets than their counterpart advantaged communities. ${ }^{33} \mathrm{In}$ our study, overweight and obesity showed highly significant association with place of residence that can also be explained by the physical activity levels of the school children. Like our study, previous study also informed that physical activity levels of school children differed based on living area. However, they also revealed seasonal variation as an influencing factor of physical activity levels among school children living in urban or rural area. ${ }^{34}$

\section{Limitations}

Several factors might influence the results of this study and considered as weakness. First, our study is a cross-sectional study in design; it only provides an association and not causation. Second, the application of convenience sampling and recalled method to collect data may elevate the risk of selection bias and recalled bias, respectively. Although we adjusted all the potential risk factors in the binary logistic regression, there are also probability of having residual confounders. Besides these, blood pressure measurement is not included in this study which is an important GVD risk factor. Due to methodological issue, the findings of this study are also not possible to generalise for all Bangladeshi school children.

\section{Strengths}

Other than these limitations, this study is important as it estimated the prevalence of CVD risk factors among school children for the first time in Bangladesh. Moreover, first time urban-rural comparison was done to show the difference of CVD risk factors burden. This study generated baseline data on CVD risk factors burden that will help the policy makers of Bangladesh to take an initiative.

\section{CONCLUSION}

Children of Bangladesh are bearing a significant burden of CVD risk factors that will add extra load on the healthcare systems. But evidence about their cardiovascular health is still insufficient that demands further large-scale nationwide study to detect the actual burden and preventive approach as appropriate.

Twitter Palash Chandra Banik @PalashChandraB7 and Sheikh Mohammed Shariful Islam @drsislam

Acknowledgements The authors would like to thank the schools authority and the parents for providing full support throughout the study period.

Contributors Conceptualisation: TMMI, PCB, MSAMA, SMSI and LB. Data curation: PCB, TMMI and SC. Data analysis: PCB, LB, SMSI and TMMI. Interpretation: PCB, LB, SC, SMSI and MSAMA. Writing —original draft: LB; Writing — review and editing: LB, SC and SMSI. All authors read and approved the final manuscript.

Funding The authors have not declared a specific grant for this research from any funding agency in the public, commercial or not-for-profit sectors.

Competing interests None declared.

Patient consent for publication Not required.

Ethics approval The study was conducted in accordance with the Declaration of Helsinki, and the protocol was approved by the Ethical Review Committee of Bangladesh University of Health Sciences (Identification number: BUHS/BIO/ EA/17/3) on 25 November 2017 (see online supplemental material 5).

Provenance and peer review Not commissioned; externally peer reviewed.

Data availability statement All data relevant to the study are included in the article or uploaded as supplementary information.

Supplemental material This content has been supplied by the author(s). It has not been vetted by BMJ Publishing Group Limited (BMJ) and may not have been peer-reviewed. Any opinions or recommendations discussed are solely those of the author(s) and are not endorsed by BMJ. BMJ disclaims all liability and responsibility arising from any reliance placed on the content. Where the content includes any translated material, BMJ does not warrant the accuracy and reliability of the translations (including but not limited to local regulations, clinical guidelines, terminology, drug names and drug dosages), and is not responsible for any error and/or omissions arising from translation and adaptation or otherwise.

Open access This is an open access article distributed in accordance with the Creative Commons Attribution Non Commercial (CC BY-NC 4.0) license, which permits others to distribute, remix, adapt, build upon this work non-commercially, and license their derivative works on different terms, provided the original work is properly cited, appropriate credit is given, any changes made indicated, and the use is non-commercial. See: http://creativecommons.org/licenses/by-nc/4.0/.

\section{ORCID iDs}

Palash Chandra Banik http://orcid.org/0000-0003-2395-9049

Lingkan Barua http://orcid.org/0000-0002-9281-3839

Sheikh Mohammed Shariful Islam http://orcid.org/0000-0001-7926-9368

\section{REFERENCES}

1 World Health Organization. Global status report on noncommunicable diseases 2010, 2015. Available: http://www.who. int/nmh/publications/ncd_report2010/en [Accessed 4 Jan 2020].

2 Prasad DS, Kabir Z, Dash AK, et al. Childhood cardiovascular risk factors in South Asians: a cause of concern for adult cardiovascular disease epidemic. Ann Pediatr Cardiol 2011;4:166. 
3 World Health Organization. Noncommunicable diseases country profiles 2011, 2015. Available: http://www.who.int/nmh/publications/ ncd_profiles2011/en/ [Accessed 4 Jan 2020].

4 World Health Organization. Ncds | stepwise approach to chronic disease risk factor surveillance, 2017. Available: http://www.who.int/ chp/steps/bangladesh/en/ [Accessed 4 Jan 2020].

5 Hujová Z, Lesniakova M. Anthropometric risk factors of atherosclerosis: differences between urban and rural east-Slovakian children and adolescents. Bratis/ Lek Listy 2011;112:491-6.

6 Scheuner MT. Genetic evaluation for coronary artery disease. Genet Med 2003;5:269-85.

7 Lind PM, van Bavel B, Salihovic S, et al. Circulating levels of persistent organic pollutants (POPs) and carotid atherosclerosis in the elderly. Environ Health Perspect 2012;120:38-43.

8 Gupta R, Misra A, Vikram NK, et al. Younger age of escalation of cardiovascular risk factors in Asian Indian subjects. BMC Cardiovasc Disord 2009;9:28.

9 The World Heart Federation,Smith S. Urbanization and cardiovascular disease: Raising heart-healthy children in today's cities, 2012. Available: http://www.worldheart.org/urbanization [Accessed 05 April 2015].

10 NCD Alliance. NCD Alliance Annual Report 2009 - 2011| NCD Alliance. Available: https://ncdalliance.org/resources/ncd-allianceannual-report-2009-2011 [Accessed 4 Jan 2020].

11 McCrindle BW. Cardiovascular consequences of paediatric obesity: will there be a future epidemic of premature cardiovascular disease? Paediatr Child Health 2007;12:175-7.

12 Anderson PM, Butcher Kristin F. (Kristin Frances), Butcher KE. Childhood obesity: trends and potential causes. Future Child 2006;16:19-45.

13 de Onis M, Onyango AW, Borghi E, et al. Development of a who growth reference for school-aged children and adolescents. Bull World Health Organ 2007;85:660-7.

14 Bendel RB, Afifi AA. Comparison of Stopping Rules in Forward 'Stepwise' Regression. J Am Stat Assoc 1977;72:46-53.

15 Costanza MC, Afifi AA. Comparison of stopping rules in forward stepwise discriminant analysis. J Am Stat Assoc 1979;74:777-85.

16 World Health Organization. Global youth tobacco survey (GYTS), Bangladesh report, 2013, 2015. Available: http://apps.who.int/iris/ handle/10665/164335 [Accessed 4 Jan 2020].

17 Khuwaja AK, Fatmi Z, Soomro WB, et al. Risk factors for cardiovascular disease in school children--a pilot study. $J$ Pak Med Assoc 2003;53:396-400.

18 Galhotra A, Abrol A, Agarwal N, et al. Life style related risk factors for cardiovascular diseases in Indian adolescents. The Internet Journal of Health 2009;9.

19 Dwivedi S, Aggarwal A, Singh N, et al. Role of family milieu in tobacco addiction: a study in a tertiary-care institution in India. $J$ Health Popul Nutr 2013;31.
20 Bulbul T, Hoque M. Prevalence of childhood obesity and overweight in Bangladesh: findings from a countrywide epidemiological study. BMC Pediatr 2014;14:86.

21 Manios Y, Dimitriou M, Moschonis G, et al. Cardiovascular disease risk factors among children of different socioeconomic status in Istanbul, Turkey: directions for public health and nutrition policy. Lipids Health Dis 2004;3:11.

22 Peltzer K, Pengpid S. Fruits and vegetables consumption and associated factors among in-school adolescents in five Southeast Asian countries. Int J Environ Res Public Health 2012;9:3575-87.

23 Peltzer K, Pengpid S. Fruits and vegetables consumption and associated factors among in-school adolescents in seven African countries. Int J Public Health 2010;55:669-78.

24 Centers for Disease Control and Prevention. Youth Risk Behavior Surveillance - United States, 2007. Available: https://www.cdc.gov/ $\mathrm{mmwr} /$ preview/mmwrhtml/ss5704a1.htm [Accessed 4 Jan 2020].

25 Ruel MT, Minot N, Smith L. Patterns and determinants of fruit and vegetable consumption in sub-Saharan Africa: a multicountry comparison. S.I.: WHO 2005.

26 George GM, Sharma KK, Ramakrishnan S, et al. A study of cardiovascular risk factors and its knowledge among school children of Delhi. Indian Heart J 2014;66:263-71.

27 Wong JE, Parikh P, Poh BK, et al. Physical activity of Malaysian primary school children. Asia Pacific Journal of Public Health 2016;28:35S-46.

28 Dixon MA, Chartier KG. Alcohol use patterns among urban and rural residents: demographic and social influences. Alcohol Res 2016;38:69-77.

29 Kelishadi R, Overweight C. Childhood overweight, obesity, and the metabolic syndrome in developing countries. Epidemiol Rev 2007;29:62-76

30 Mazhar H, Sabnis R, Sahu K, et al. Urban and rural disparity in tobacco use and knowledge about oral cancer among adolescents: an epidemiological survey on 12 and 15-year school going students. Journal of International Society of Preventive and Community Dentistry 2016;6:226.

31 Singh KM, Singh M. Singh K. anthropometric characteristics and body composition of the rural and urban children. Int J Curr Res Rev 2017:9:33-8.

32 Colić-Barić I, Kajfež R, Satalić Z, et al. Comparison of dietary habits in the urban and rural Croatian schoolchildren. Eur $J$ Nutr 2004:43:169-74.

33 Rasmussen M, Krølner R, Klepp K-I, et al. Determinants of fruit and vegetable consumption among children and adolescents: a review of the literature. Part I: qualitative studies. International Journal of Behavioral Nutrition and Physical Activity 2006:3-22.

34 Loucaides CA, Chedzoy SM, Bennett N. Differences in physical activity levels between urban and rural school children in Cyprus. Health Educ Res 2004;19:138-47. 